\title{
La competencia mediática en educación primaria en el contexto español'
}

Antonia Ramírez Garcíall

Jacqueline Sánchez-Carrero"II

Paloma Contreras-Pulido ${ }^{\text {N }}$

I- Estudio enmarcado en la Convocatoria de

\section{Resumen}

Desde hace casi cuatro años un numeroso grupo de investigadores españoles de más de veinte universidades del país estudian los niveles de competencia mediática de la ciudadanía para promover así programas de alfabetización mediática en las escuelas y entornos no formales. La competencia mediática es un concepto que abarca nuestras habilidades y conocimientos frente a los medios de comunicación y puede ser medida a través de seis dimensiones: lenguaje, tecnología, producción y programación, recepción y audiencias, ideología y valores y finalmente la estética. Concretamente, en el estudio descriptivo que aquí se presenta, se explora el grado de dicha competencia en el caso concreto de escolares de cuarto de Educación Primaria de entre nueve y diez años, en el contexto español. Para ello fue necesario el diseño e implementación de un cuestionario online, adaptado a sus edades tanto en el contenido como en el diseño, para poder conocer si los 581 participantes que componen la muestra son competentes desde el punto de vista mediático. Los resultados muestran que nada es lo que parece. Pese a lo que se pudiera suponer, es necesario una mayor formación en medios entre el alumnado de esta etapa obligatoria y por tanto se precisan programas de alfabetización mediática en las escuelas y también en los entornos familiares.

\section{Palabras clave}

Competencia mediática - Educación primaria - Evaluación.

Proyectos I+D del Ministerio de Economía

y competitividad con clave: EDU2010-

21395-C03-03 y en el Proyecto de

Investigación de Excelencia de la Junta de Andalucía SEJ-5823-2010.

II- Universidad de Córdoba, Córdoba, España.

Contacto: ed1ragaa@uco.es

III- Universidad Internacional de Andalucía, Sevilla, España.

Contacto: jsanchezcarrero@gmail.com

IV- Universidad de Huelva, Huelva, España.

Contacto: paloma.contreras.pulido@gmail.com 


\title{
Media competence in primary education in the Spanish context
}

\author{
Antonia Ramírez Garcíal \\ Jacqueline Sánchez-CarrerollI \\ Paloma Contreras-Pulido"
}

\begin{abstract}
For almost four years, a large group of Spanish researchers from over twenty universities in Spain has been studying the population's levels of competence in media in order to promote media literacy programs in schools and non-formal settings. The concept of media literacy encompasses our skills and knowledge on the media and can be measured by six dimensions: language, technology, production and programming, reception and audiences, ideology and values, and finally aesthetics. This descriptive study explores the extent of those competences in the context of fourth grade students, aged nine and ten years in Spain. It was necessary to design an online questionnaire whose content and design was adapted to their age, to know whether the 581 participants in the sample are competent from a media point of view. The results show that nothing is what it seems. Despite what one might assume, further training in media is necessary for students of this compulsory education level. Therefore, media literacy programs are needed in schools and households.
\end{abstract}

\section{Keywords}

Media literacy - Primary education - Assessment.

I- Study prepared for the Call for Projects I+D of the Economy and Competitiveness Ministry (EDU2010-21395-C03-03) and for project of Reserch on Excellence of Junta de Andalucía SEJ-5823-2010.

II- Universidad de Córdoba, Córdoba, España.

Contact: ed1ragaa@uco.es

III- Universidad Internacional de Andalucía, Sevilla, España.

Contact: jsanchezcarrero@gmail.com

IV- Universidad de Huelva, Huelva, España.

Contact: paloma.contreras.pulido@gmail.com 


\section{Introducción}

Desde hace algunos años, la preocupación por la formación de los ciudadanos en su interacción con los medios de comunicación ha ido incrementándose. Al mismo tiempo, se hace evidente la falta de un consenso real y una apuesta verdadera por implementar políticas educativas encaminadas a un mayor desarrollo para adquirir competencias en este ámbito. Pero, poco a poco se están propiciando iniciativas dirigidas sobre todo al análisis e investigación de aspectos vinculados al mismo, con el objetivo de poder adoptar decisiones por parte de las instituciones públicas a favor de un mayor empoderamiento ciudadano frente al mundo mediático.

En este artículo se exponen los resultados de una investigación realizada en el marco de un proyecto $\mathrm{I}+\mathrm{D}$ titulado $L a$ competencia en comunicación audiovisual en un entorno digital. Diagnóstico de necesidades en tres ámbitos sociales, coordinado por Joan Ferrés de la Universidad Pompeu Fabra. Concretamente, el estudio que presentamos emana de uno de los subproyectos de este $\mathrm{I}+\mathrm{D}$, el denominado La enseñanza obligatoria ante la competencia en comunicación audiovisual en un entorno digital, dirigido por Ignacio Aguaded y en el que han participado investigadores de diecisiete universidades españolas.

El proyecto en el que se basa este artículo tiene como objetivo implementar en la comunidad educativa no universitaria el concepto de competencia audiovisual, diagnosticando rigurosamente el punto de partida, detectando las necesidades formativas y estableciendo un amplio programa evaluativo que derive en propuestas formativas ciudadanas. Uno de los colectivos estudiados ha sido el compuesto por niños y jóvenes españoles que cursan estudios en las etapas de Educación Infantil, Educación Primaria, Secundaria y Bachillerato.

En este artículo nos centraremos en los resultados que han surgido de la implementación de un cuestionario suministrado vía online, que evalúa el grado de competencia mediática en niños de cuarto de educación primaria de 10 provincias españolas (Cantabria, Córdoba, Granada, Huelva, La Rioja, Lugo, Málaga, Murcia, Sevilla y Valencia), teniendo como base las seis dimensiones sobre competencia en comunicación audiovisual elaboradas por Ferrés (2007): el lenguaje, la tecnología, los procesos de producción y programación, la ideología y valores, la recepción y audiencia y, por último, la dimensión estética.

\section{Marco teórico}

Que estamos ante una revolución tecnológica, nadie lo niega. La relación entre la ciudadanía y los medios de comunicación, tradicionales y nuevos, ha cambiado de forma radical. Esto se hace notar sobre todo en la población más joven, son ellos los potenciales consumidores y usuarios más activos en todo lo concerniente al mundo mediático. Ya Prensky (2001) los llamó nativos digitales, aunque tal denominación no conlleve a la comprensión del medio digital: "los jóvenes manejan los medios digitales en ausencia o con un bajo conocimiento del poder audiovisual" (apud AGUADED; PÉREZ, 2012, p. 25). De ahí la importancia de una verdadera alfabetización mediática, estructurada y planificada en políticas educativas que incidan en ella, ya que "si el niño se forma para estar alfabetizado audiovisualmente, sabrá defenderse de aquellos mensajes que le resulten no sólo poco apropiados para su nivel de desarrollo, sino también de los que intenten fomentar contravalores, estereotipos o falsedades" (MARTA, 2008, p. 38).

El concepto de alfabetización mediática, recogido en la Resolución del Parlamento Europeo de 2009 sobre La alfabetización mediática en el entorno digital para una industria audiovisual y de contenidos más competitiva y una sociedad del conocimiento incluyente apunta que

[...] la alfabetización mediática está relacionada con la capacidad de acceder a los medios de comunicación, comprender y evaluar con criterio diversos aspectos de los mismos y de sus contenidos, así como de establecer formas 
de comunicación en diversos contextos.

(Comisión Europea, 2013, p. 4).

Además, aclara que en este concepto se incluyen todos los medios de comunicación con los que la ciudadanía interactúa hoy día, así como que es clave la implicación de los Estados para decidir cómo incorporar la alfabetización mediática a los planes de estudio escolares de todos los niveles, además de promoverla en adultos y en toda la sociedad en general.

Para que lo anterior se lleve a cabo es necesario conocer el grado de competencia actual de la población y así llegar a implementar programas educativos que beneficien esa alfabetización mediática. Hasta ahora, la competencia audiovisual, en general, ha sido un ámbito escasamente estudiado y preocupa sobremanera la relación que los colectivos más vulnerables, como los niños y adolescentes, mantienen hoy día con el mundo mediático

En un entorno social mediado por las pantallas habría que capacitar a los ciudadanos y ciudadanas para que sepan interaccionar de manera madura con los mensajes ajenos y para que sean capaces de producir y de difundir mensajes que contribuyan al desarrollo personal y a la mejora del entorno social (FERRÉS; AGUADED; GARCÍA, 2012, p. 41).

El concepto de competencia mediática se mantiene en un constante debate entre investigadores vinculados principalmente al ámbito de la comunicación y la educación, que intentan delimitar qué significa hoy día que una persona sea verdaderamente competente a la hora de enfrentarse a un medio de comunicación (PÉREZ; DELGADO, 2012).

Ferrés definió el término Competencia Audiovisual como:

La capacidad de un individuo para interpretar y analizar desde la reflexión crítica las imágenes y los mensajes audiovisuales, y para expresarse con una mínima corrección en el ámbito comunicativo. Esta competencia está relacionada con el conocimiento de los medios de comunicación y con el uso básico de las tecnologías multimedia necesarias para producirla. (FERRÉS, 2007, p. 10).

Ya entonces el autor había delimitado seis dimensiones e indicadores en cada una de ellas que servirían para evaluar el grado de competencia mediática de la ciudadanía y que han sido posteriormente actualizadas por el propio Ferrés y Piscitelli:

La competencia mediática comporta el dominio de conocimientos, destrezas y actitudes relacionados con seis dimensiones básicas, de las que se ofrecen los indicadores principales. Estos indicadores tienen que ver, según los casos, con el ámbito de participación como personas que reciben mensajes e interaccionan con ellos (ámbito del análisis) y como personas que producen mensajes (ámbito de la expresión). (FERRÉS; PISCITELLI, 2012, p. 79).

\section{Investigaciones realizadas en torno a la educación mediática}

En el contexto de la educación mediática se puede observar la proliferación de estudios que se ocupan de investigar el tema, sobre todo, los que tienen como destinatarios a los más jóvenes.

En el ámbito europeo, hay que destacar especialmente el papel de los organismos internacionales como la Comisión Europea, con trabajos como Study on the current trends and approaches on media literacy in Europe, con la finalidad de conocer el estado de la cuestión e identificar las tendencias en materia de alfabetización mediática dentro de la Unión Europea ${ }^{1}$. En la línea de la reflexión crítica, en Reino Unido cabría destacar a Masterman y el British Film Institute (BFI) ${ }^{2}$, especialmente

1- http://g00.gl/cVn4pN

2-http://www.bfi.org.uk 
a Bazalgette y Buckingham quienes desde mediados de la década de los noventa han dirigido proyectos de investigación internacionales como Children's media culture: education, entertainment and the public sphere o pokemon and children's global culture. En Francia sobresalen los trabajos de investigadores como Jacquinot-Delaunay, Gonnet y Bevort, estos dos últimos en el seno del CLEMI (Centre de Liason de l'Enseignement des Médias d'Information) ${ }^{3}$, que han sido clave durante más de veinte años para entender la educación en medios en el ámbito francófono, tanto desde una perspectiva formativa como de publicaciones e investigaciones.

En Suecia, destacan los trabajos de Von Feilitzen y Carlson (1999), en The UNESCO international clearinghouse on children and violence on the screen ${ }^{4}$. En Bélgica, los trabajos realizados en Media Animation ${ }^{5}$, los de Michel Clarembeaux en el Centre Audiovisuel de Liège $^{6}$ y de Thierry De Smedt en la Université Catholique de Louvain. En Portugal son referentes investigadores de reconocido prestigio como Reia en el Centro de Investigação em artes e comunicação de la Universidade do Algarve ${ }^{7}$, Pinto y Pereira de la Universidade do Minho y Mendes da Ponte de la Universidade Nova de Lisboa. Mientras que en Italia, se reconocen los trabajos de Rivoltella de la Università Cattolica del Sacro Cuore. No obstante, en el ámbito de la educación mediática, además de las investigaciones que se desarrollan en cada país, se ha iniciado recientemente, al amparo de la Comisión Europea, otros proyectos conjuntos a través de convocatorias de la Education, Audiovisual \& Culture Executive Agency $^{8}$, con líneas de acción como Digital Literacy, Audiovisual and Media Policies, que han generado proyectos internacionales como

\footnotetext{
3- http://www.clemi.org

4- http://goo.gl/vpYJyr

5- http://www.media-animation.be/

6- http://www.cavliege.be/

7- http://www.ciac.pt

8- http://eacea.ec.europa.eu/index_en.php
}

Euromeduc con el reciente trabajo L'education aux médias en Europe?

También resulta interesante señalar los estudios y trabajos de los investigadores independientes de la Euro Media Literacy ${ }^{10}$ con la Carta Europea de Alfabetización Mediática ${ }^{11}$, publicada en el año 2007 en Bruselas. Finalmente, conviene resaltar la labor de la European Association for Viewers Interests (EAVI) ${ }^{12}$, creada en Bruselas en 2004 por un consorcio de expertos de los medios y el respaldo de la Comisión Europea. Entre sus estudios más recientes despunta una serie de criterios para medir los niveles de alfabetización en los países europeos, especialmente en los 27 Estados miembros de la Unión Europea, evaluar tales niveles y proponer medidas políticas para potenciar la alfabetización mediática.

En América Latina, los grupos de investigación en esta temática se han acrecentado en las dos últimas décadas. Los trabajos de Freire (Brasil), continuados en educación mediática por Kaplún (Uruguay) y Martín Barbero (Colombia), se han visto reflejados también en los estudios de audiencia de Orozco (México). Siguen una línea similar en educación en medios los estudios de Hernández (Venezuela), Quiroz (Perú), Bustamante (Colombia), Merlo, Novelli y Funes (Argentina), Fontcuberta y Avendaño (Chile), De Oliveira, Quintão y Esperon (Brasil) entre un variado abanico de investigadores que han compuesto un profuso corpus científico de antecedentes que fundamentan, sin duda, este estudio sobre competencias audiovisuales de la ciudadanía, y en especial de la infancia.

En España, otro grupo de investigadores ha centrado sus trabajos en la necesidad de la educación en medios y la responsabilidad social de los diferentes agentes sociales. Aparici en la Universidad de Educación a Distancia UNED (Madrid), García Matilla (Universidad

\footnotetext{
9 - http://www.media-animation.be/IMG/pdf/Euromeduc_FR.pdf

10- http://www.euromedialiteracy.eu/

11- http://redalyc.uaemex.mx/pdf/158/15802819.pdf

12- http://www.eavi.eu/
} 
de Valladolid), Ferrés (Universidad Pompeu Fabra), Pérez Tornero (Universidad Autónoma de Barcelona) y Aguaded (Universidad de Huelva) han liderado diferentes estudios en este campo. Grupos de investigación como Drac Magic (Barcelona), Aire (Madrid), Spectus (Aragón), Grupo Comunicar (Andalucía), Mitjans (Cataluña), Apuma (Estatal), Eko Kolektiboa (País Vasco), estos constituyen muestras palpables del dinamismo de esta temática. Hay que destacar también el importante papel jugado por el CNICE (Centro Nacional de Información y Comunicación Educativa) del Ministerio de Educación en España, hoy convertido en ITE $^{13}$ (Instituto de Tecnologías Educativas), el Instituto RTVE ${ }^{14}$ con sus seminarios y reuniones de expertos y el Consejo Audiovisual de Cataluña (CAC), que ha sido pionero y ha implantado acciones en alfabetización mediática desde sus inicios.

Por último, queremos destacar el trabajo que, a nivel español, se ha llevado a cabo entre el año 2005 y el 2010, como iniciativa pionera en este ámbito. El CAC y el Ministerio de Educación financiaron la investigación titulada Competencia Mediática. Investigación sobre el grado de competencia de la ciudadanía en España ${ }^{15}$. El estudio, que se coordinó desde la Universidad Pompeu Fabra y en el que participaron diecisiete universidades de cada una de las comunidades autónomas de España, tenía el objetivo de evaluar el grado de competencia en materia audiovisual de la ciudadanía española a través de distintas herramientas metodológicas y diferentes análisis -cuantitativo y cualitativo-.

En la actualidad, esta investigación se encuentra complementada a través del proyecto I+D del Ministerio de Economía y Competitividad de España, con clave: EDU2010-21395-C03, del que presentamos aquí algunos resultados.

\footnotetext{
13- http://novedades.cnice.mec.es

14- http://www.rtve.es/instituto/

15- http://ntic.educacion.es/w3//competencia_mediatica/
}

\section{Objetivos e hipótesis}

Tres fueron los objetivos que se redactaron para esta investigación:

1. Determinar el conocimiento de los escolares de cuarto de educación primaria sobre algunos aspectos relacionados con los medios de comunicación de acuerdo con las dimensiones establecidas por Ferrés (2007: 2) para evaluar la competencia mediática.

2. Diseñar un cuestionario para medir dicha competencia en estudiantes de cuarto de educación primaria.

3. Indagar sobre las posibles causas que pueden incidir en el nivel de competencia mediática de dicho alumnado.

Es lógico preguntarse, en consecuencia, si existen diferencias significativas en función de variables como el género, la edad, el centro educativo de pertenencia o la localidad donde vive.

\section{Método}

\section{Metodología y diseño}

La metodología utilizada para esta investigación se enmarca dentro de lo que se conoce como metodología empírico-analítica, puesto que se fundamenta en la experimentación con un posterior análisis estadístico. Uno de los métodos más utilizados en este tipo de estudios donde lo que se pretende es conocer y explicar una realidad concreta, así como poder establecer ciertas generalizaciones que puedan predecir comportamientos posteriores en los participantes de la investigación, es la encuesta. En esta ocasión se utilizó un cuestionario online. Asimismo, esta investigación sigue un diseño no experimental, correlacional y descriptivo, de acuerdo con lo establecido por García Llamas (2003), Bisquerra (2004) y Martínez González (2007).

El proceso de experimentación se centra en las siguientes fases de investigación: planteamiento del problema, definición de objetivos, formulación de interrogantes, identificación y conceptualización de variables, diseño de la investigación propiamente dicha, 
descripción de la muestra, delimitación del instrumento de recogida de información y aplicación de las técnicas de análisis de datos.

\section{Población y muestra}

En cuanto a la población, se puede señalar que estaba constituida por los escolares que cursaban el cuarto nivel de educación primaria residentes en nuestro sistema educativo. Concretamente, la muestra estaba compuesta por alumnos del nivel de cuarto de educación primaria pertenecientes a diez provincias españolas: Cantabria, Córdoba, Granada, Huelva, La Rioja, Lugo, Málaga, Murcia, Sevilla y Valencia ( $\mathrm{N}=581)$. Es relevante la participación de las principales provincias españolas que aporta una idea de la importancia de este estudio de ámbito nacional. El perfil de los participantes se puede describir desde tres aspectos diferentes: la edad de los miembros de la muestra, el género y la titularidad del centro escolar. La muestra estuvo compuesta por niños de 10 años (50,1\%) y de 9 años de edad (42,2\%); $45,6 \%$ niños y 54,4\% niñas. En cuanto a la titularidad del centro en el que se encuentran matriculados el 57,3\% lo está en un colegio público, el $38,2 \%$ en un centro concertado (privado pero con financiación pública) y el $4,5 \%$ en una institución educativa privada.

\section{Las variables}

Las variables de estudio independientes son: provincia, sexo, edad y titularidad del centro. En lo que concierne a las variables dependientes, estas se han distribuido en las seis dimensiones establecidas por Ferrés (2007). Es conveniente recordar que para el autor estas dimensiones suponen un punto de análisis y deben ser vinculadas entre sí. Es decir, no deben concebirse como compartimentos estancos, como elementos separados, sino que cada una de ellas existe si está en relación con las demás.

La dimensión denominada Lenguaje se entiende como aquellos "conocimientos de los códigos que hacen posible el lenguaje audiovisual y capacidad de utilizarlos para comunicarse de manera sencilla pero efectiva" (FERRÉS, 2007, p. 103). En cuanto a la capacidad de análisis se refiere a su desarrollo teniendo como enfoque el sentido y la trascendencia de la narrativa con sus correspondientes categorías y géneros. La siguiente dimensión es la Tecnología y se define para esta investigación como "el conocimiento teórico del funcionamiento de las herramientas que hacen posible la comunicación audiovisual, para poder entender cómo son elaborados los mensajes" ( $p, 103)$. Esta tiene relación no únicamente con la teoría, sino también con la capacidad de saber utilizar las herramientas menores para establecer una comunicación eficiente en el campo audiovisual.

Otra de las dimensiones, la referida a los Procesos de producción y programación, pone el énfasis en los "conocimientos de las funciones y tareas asignadas a los principales agentes de producción y las fases en las que se descomponen los procesos de producción y programación de los distintos tipos de productos audiovisuales" (p. 103). Asimismo, tiene que ver con la producción de documentos audiovisuales, es decir, la capacidad de elaboración de mensajes a través de este medio y la adquisición de conocimientos sobre la importancia de los nuevos ambientes de la comunicación.

Existe otro ámbito especial en la educación mediática que también es considerada por Ferrés (2007) y es lo que denomina Ideología y valores. Se refiere a la capacidad de comprender y ser crítico ante las pantallas puesto que transmiten de modo intrínseco ideologías y valores al representar la realidad. $\mathrm{Al}$ mismo tiempo, hace referencia a la "capacidad de análisis crítico de los mensajes audiovisuales, entendidos a un tiempo como expresión y soporte de los intereses, de las contradicciones y de los valores de la sociedad" (p. 103). Como Recepción y audiencia se reconoce otra de las dimensiones de análisis, aquella que logra el individuo cuando desarrolla su "capacidad de reconocerse como audiencia activa, especialmente a 
partir del uso de las tecnologías digitales que permiten la participación y la interactividad" (p. 103). También toma en cuenta la capacidad de valoración crítica como los mensajes que afectan a la emoción, el raciocinio o los contextuales, que complementan el mensaje de los medios. Por último, hace referencia a la Dimensión Estética como la que analiza y valora los mensajes "desde el punto de vista de la innovación formal y temática y la educación del sentido estético" (p. 103). También se toma en consideración la capacidad de la persona de relacionar los mensajes audiovisuales con otras expresiones artísticas y de los medios de comunicación.

\section{Instrumentos}

La base de esta investigación es un cuestionario compuesto por diversos items con respuestas de opción múltiple, que desplegamos en la Tabla 1.

El cuestionario diseñado para esta investigación $\mathrm{y}$ disponible online ${ }^{16}$, fue el resultado de las siguientes fases de trabajo.

El cuestionario diseñado para esta investigación $\mathrm{y}$ disponible online ${ }^{17}$, fue el resultado de las siguientes fases de trabajo.

Fase 1. Diseño inicial del cuestionario. El diseño del cuestionario se fundamentó en el elaborado anteriormente para los miembros del Proyecto titulado Competencia Mediática. Investigación sobre el grado de competencia de la ciudadanía en España (FERRÉS et al., 2011) en el que intervinieron representantes de diecisiete universidades de España, tal como se menciona en el punto Investigaciones realizadas en torno a la Educación Mediática. Partiendo de éste, nuestra

16- http://www.uhu.es/competenciamediatica/primaria/

17- http://www.uhu.es/competenciamediatica/primaria/

Tabla 1- Dimensiones para medir la competencia mediática según Ferrés (2007) y los respectivos ítems diseñados para esta investigación

\begin{tabular}{|c|c|}
\hline Dimensión & Ítem \\
\hline \multirow{2}{*}{ Lenguaje } & $\begin{array}{l}\text { Después del visionado de un anuncio publicitario: ¿Por qué crees que le puede gustar a la gente el anuncio de los } \\
\text { niños cantando? (Válida para dos dimensiones). }\end{array}$ \\
\hline & Ante dos fotografías; ¿Por qué has elegido esa fotografía? \\
\hline \multirow{4}{*}{ Tecnología } & Elige la opción que corresponda a la definición correcta de los siguientes términos: SMS, DVD, You Tube, Ipod. \\
\hline & Observa estas 2 imágenes. ¿Cómo crees que se ha logrado la imagen 2? \\
\hline & $\begin{array}{l}\text { Elige la función correspondiente a cada uno de los siguientes botones (Play, Retroceder, Adelantar, Pausa, Stop, No } \\
\text { sé). }\end{array}$ \\
\hline & ¿Para qué utilizas Internet? \\
\hline \multirow{3}{*}{$\begin{array}{l}\text { Recepción y } \\
\text { Audiencia }\end{array}$} & $\begin{array}{l}\text { Después del visionado de dos anuncios publicitarios. ¿Crees que el anuncio del niño y el mar te convence a ti y a } \\
\text { otras personas para comprar Nesquik? }\end{array}$ \\
\hline & ¿Por qué crees que te gusta el anuncio del niño y el mar? \\
\hline & ¿A qué se llama Audiencia de un programa de TV? \\
\hline \multirow{4}{*}{$\begin{array}{l}\text { Procesos de } \\
\text { Producción y difusión }\end{array}$} & Elige la opción que corresponda a la función que realizan los profesionales de la tele. \\
\hline & El casting para una serie de televisión consiste en escoger... \\
\hline & ¿Qué es una copia pirata? \\
\hline & Si tuvieras que presentar una peli a un concurso ¿cómo ordenarías los pasos para realizarla? \\
\hline \multirow{2}{*}{ Ideología y valores } & ¿En qué piensas cuando ves el anuncio del niño y el mar? Marca una sola respuesta. \\
\hline & ¿Por qué crees que le puede gustar a la gente el anuncio de los niños cantando? (Válida para dos dimensiones). \\
\hline \multirow{2}{*}{ Estética } & Después del visionado de dos anuncios. ¿Cuál de estos dos anuncios de la tele te gusta más? \\
\hline & ¿Por qué has escogido ese anuncio? \\
\hline
\end{tabular}

Fuente: Elaboración propia. 
función fue, por un lado, adaptar los ítems a las edades de los niños que eran nuestro punto de interés, puesto que el anterior estaba destinado a mayores de 16 años; por otro lado, reducir el número de preguntas, ya que estaba dirigido a niños cuya edad media estaría entre 9 y 10 años.

Primero se diseñó en papel $\mathrm{y}$, tras su pilotaje, se trabajó en la versión digital para su implementación online. En este sentido, el esfuerzo se centró en reducir la redacción de las preguntas a su mínima expresión, proporcionar una navegación atractiva y sencilla y, por último, utilizar un diseño gráfico infantil sobre el que se mostrara una pregunta por pantalla. De esta manera, se evitaría la dificultad y el consecuente rechazo que puede producir una pantalla repleta de preguntas para un niño de 9 ó 10 años.

En la primera versión el cuestionario contaba con 31 preguntas que fueron sometidas a análisis por el grupo de investigación Ágora, de la Universidad de Huelva. La validación se llevó a cabo mediante la técnica Delphi por todos los miembros de dicho Proyecto, formado por veintitrés integrantes, cuyas especialidades abarcan los campos de la educación universitaria y la comunicación audiovisual, y pertenecientes a las siguientes provincias participantes: Cantabria, Córdoba, Granada, Huelva, La Rioja, Lugo, Málaga, Murcia, Sevilla y Valencia.

La valoración fue positiva en su conjunto, el aspecto menos efectivo se refería a preguntas de selección que podían llevar a confusión debido a que las opciones de respuesta eran parecidas y el niño no podía diferenciarlas. También fueron eliminadas aquellas preguntas abiertas que podían presentar una variedad muy alta de respuestas y se desconocía si realmente contribuirían a los resultados. Como consecuencia se eliminaron doce preguntas y se reagruparon cuatro en solo dos. Otro de los cambios se hizo sobre aquellos interrogantes que hacían referencia a la ilusión de invulnerabilidad. La primera preguntaba si creía que uno de los anuncios publicitarios visionados le convencería a él (o ella) del producto, mientras que la segunda formulaba el mismo interrogante pero referido no a él mismo, sino a los demás.
Se decidió agruparlas e incluir opciones de respuesta que abarcaran ambas posibilidades. De este proceso resultaron finalmente diecinueve preguntas que fueron las que constituyeron el instrumento para el pilotaje.

Fase 2. Pilotaje del cuestionario. La prueba piloto se realizó a veinticinco estudiantes de un grupo natural de cuarto de educación primaria pertenecientes al CEIP - Colegio de Educación Infantil y Primaria Tirso de Molina (Córdoba). El proceso de llevó a cabo durante un tiempo total de 45 minutos, aunque hay que reconocer que el cuestionario propiamente dicho requiere una media de 10 a 15 minutos para su cumplimentación. El proceso se efectuó correctamente, con apenas algunas incidencias. Una, relacionada con el tema de las redes sociales, ya que algunos niños no conocían Tuenti o Facebook. La otra tuvo que ver con uno de los spots publicitarios cuyo producto anunciado era una galleta. La primera reacción que los niños tuvieron fue la identificaron con el sabor del producto -galletas de chocolate- de uno de los anuncios, dejando de lado la posibilidad de responder con lógica o establecer comparaciones entre ambos. Su respuesta se basó en el gusto por el chocolate y no por los aspectos estéticos o de contenido que pretendíamos que apreciaran. La decisión fue, naturalmente, realizar una nueva búsqueda de anuncios que fueran realmente útiles en esa ocasión.

Fase 3. Diseño definitivo del cuestionario. Teniendo presente lo anterior remodelamos algunas preguntas, como la de las redes sociales, y cambiamos los anuncios publicitarios que promovían un mismo producto, pero a través de dos spots muy distintos, uno de ellos se prestaba para la apreciación estética a diferencia del otro ${ }^{18}$. Después de renovar el cuestionario haciendo

18 - Uno de los anuncios lo titulamos Niños cantando cuyo lema era: Échale Nesquiky es un videoclip que combina la acción de actores y dibujos de animación. El segundo spot que llamamos El niño y el mar muestra al personaje en animación 3D y un niño que mira por la ventana en un día lluvioso y mientras consume la bebida se imagina a sí mismo atravesando los mares montado en una ballena en medio de otros animales marinos que vuelan. Este anuncio con el slogan Dentro de ti está la diversión, dentro de Nesquik el sabor fue producido por el mercado audiovisual latinoamericano a propósito del Día de la Niñez. 
las modificaciones pertinentes se procedió a la aplicación del instrumento definitivo, constituido por veintidós preguntas cerradas, de opción múltiple. De estas veintidós preguntas, diecisiste abarcaban la materia en cuestión y las otras cinco eran de carácter nominativo, es decir, tenían que ver con las características de la muestra y con el lugar de aplicación.

Tanto en la fase provisional como en la definitiva el cuestionario se encontraba acompañado de una rúbrica de evaluación que medía las respuestas dadas por el alumnado de acuerdo con unos criterios preestablecidos y que hacían referencia al grado de competencia que mostraba el alumnado. En cuanto al índice de fiabilidad, el cuestionario ha arrojado un alfa de Cronbach de 0.787.

\section{Procedimiento}

Durante quince días se llevó a cabo la aplicación online del cuestionario simultáneamente en las diez provincias participantes. Los centros educativos fueron seleccionados en función de su ofrecimiento para participar en el proyecto, su titularidad y la disponibilidad de Internet en los mismos. El segundo paso, después de la aplicación del cuestionario fue vaciar la base de datos generada por el sistema online y elaborar su correspondiente libro de códigos. Posteriormente, las respuestas fueron re-categorizadas con el programa estadístico SPSS (v.18) de acuerdo con la rúbrica de evaluación diseñada previamente durante el desarrollo de la creación del cuestionario. Este último paso permitió realizar un análisis estadístico a través de porcentajes, tablas de contingencia, chi-cuadrado de Pearson, coeficiente de contingencia, Phi y V de Cramer.

\section{Resultados}

Para poder indagar sobre los resultados de esta investigación, conviene conocer el comportamiento de los miembros de la muestra en cada una de las preguntas del cuestionario para, posteriormente, mostrar el grado de competencia mediática que manifiesta el alumnado de cuarto de educación primaria en España. Por último, describiremos las relaciones existentes entre algunas de las distintas variables.

Tal y como se comentó, las cinco primeras preguntas son nominativas, en consecuencia comenzamos describiendo las respuestas a partir de la pregunta número 6 , la cual mide la Dimensión Estética. En cuanto a la elección de los anuncios propuestos a los participantes, el 25,6\% seleccionó el anuncio 1 (El niño y el mar), mientras que el 74,4\% eligió el anuncio 2 (Niños cantando). Entre los motivos de la elección (pregunta 6.1) destaca la música es alegre en un 44,9\%, porque le gusta más (sin ninguna razón) en un 32,9\%, se parece a una película en un 14,5\% y, finalmente, porque el Nesquik es bueno, es decir porque le gusta el producto, en un 7,7\%.

$\mathrm{Si}$ agrupamos los resultados de la respuesta que definía el enfoque estético y el no estético obtenemos la Figura 1. Si desglosáramos el enfoque no estético, podríamos obtener un resultado medio en el cual observamos que un $44,9 \%$ de los niños atribuye a la música el factor más atrayente del anuncio, lo cual también significa que no cuenta con un enfoque desde el punto de vista estético, según las dimensiones antes citadas. Merece la pena mencionar que un $32,9 \%$ de la muestra no es capaz de identificar la razón por la que escogió el anuncio. Si observamos la media entre estas dos preguntas, el alumnado cuenta con un enfoque no estético en su mayoria, 79,95\%, y un enfoque estético en un $20,05 \%$. El porcentaje de preguntas se puede ver en la Figura 1 y su resumen en la Figura 2.

Al plantearle al alumnado de cuarto de educación primaria en qué piensa cuando ve el anuncio de El niño y el mar (pregunta 6.2), de forma mayoritaria afirman que con la imaginación se puede vivir aventuras (65,7\%). Conviene señalar que un $17,4 \%$ de la muestra manifestó no pensar en nada cuando visionó el citado anuncio. Esta pregunta es significativa para la Dimensión Ideología y Valores junto 
Figura 1- Preguntas de la Dimensión Estética

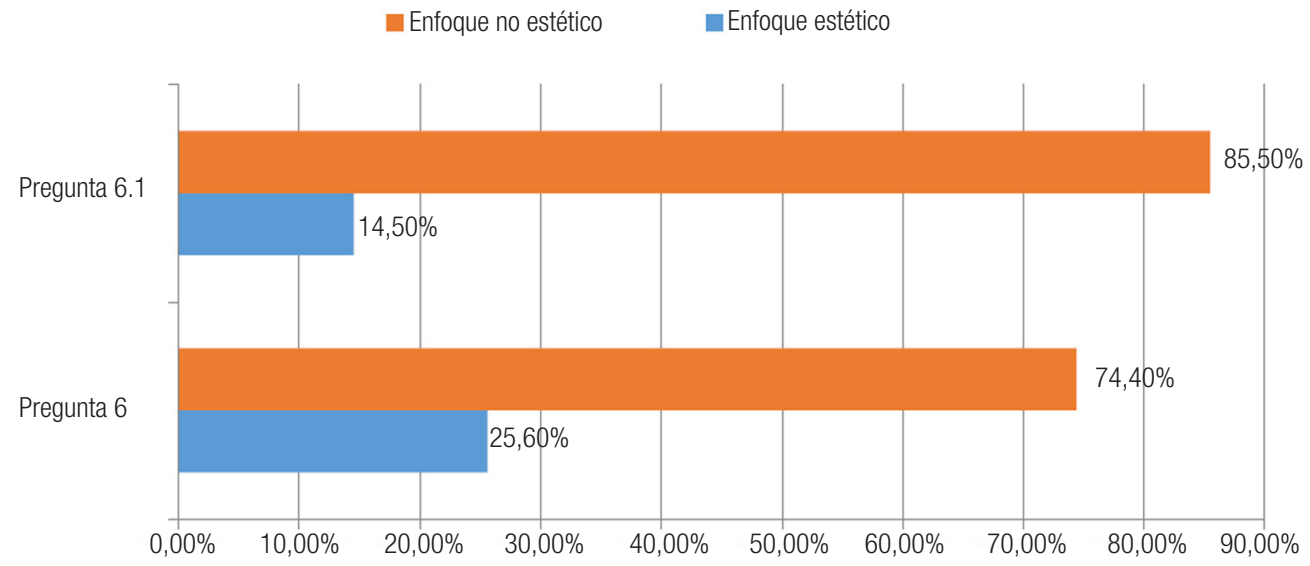

Fuente: Elaboración propia.

Figura 2- Resumen de las preguntas que forman la Dimensión Estética

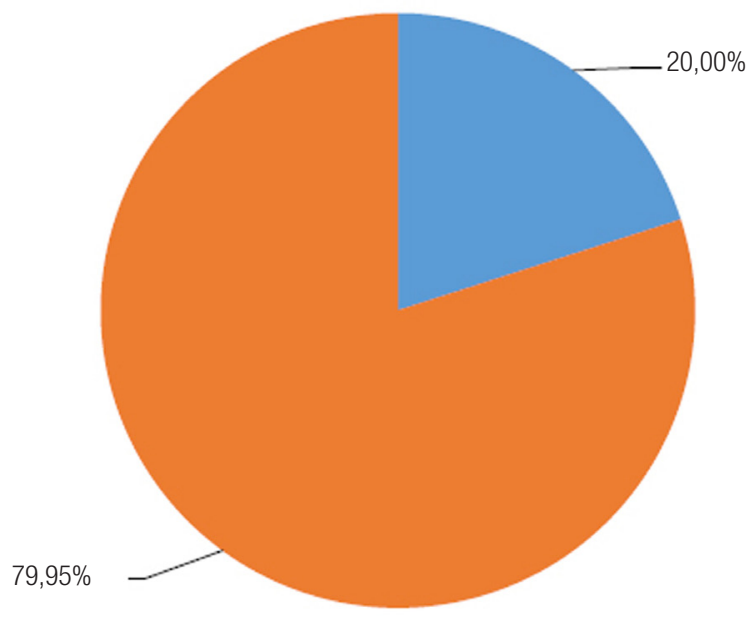

Fuente: Elaboración propia

con la siguiente, la 6.3: ¿Por qué crees que le puede gustar a la gente este anuncio? En realidad, la mayoría responde adecuadamente a este interrogante, bien desde el punto de vista de ideología y valores $(41,0 \%)$, bien desde el enfoque del lenguaje audiovisual (44,6\%), pues este item mide ambas dimensiones en sus opciones de respuesta. Un 4,5\% prefirió responder no sé a esta pregunta. Véase el porcentaje de respuestas de cada uno de los items que constituye esta dimensión en la Figura 3 y el resumen en la Figura 4. 
Figura 3- Preguntas de la Dimensión Ideología y Valores

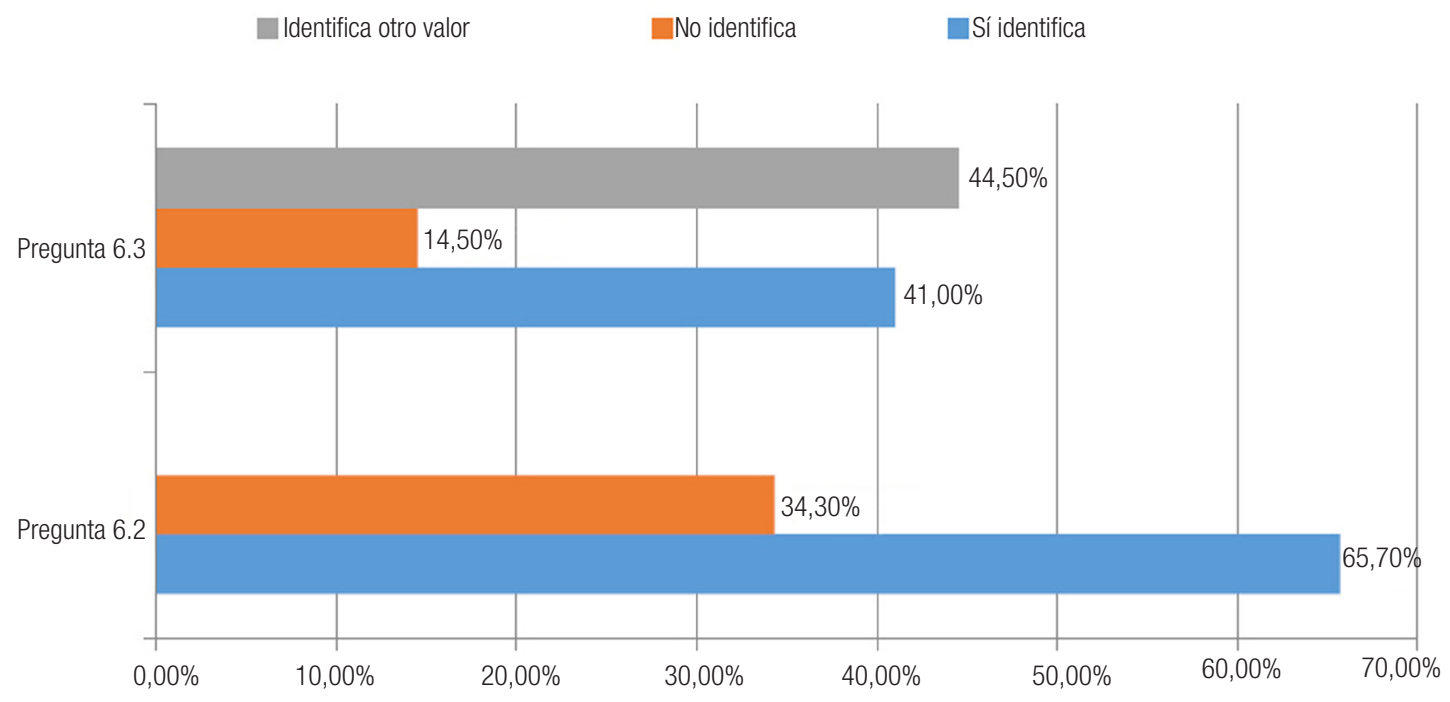

Fuente: Elaboración propia.

En resumen, en relación a la Dimensión Ideología y Valores, la mayoría de los participantes $(53,35 \%)$ identificó correctamente la opción sobre dicha dimensión. El resto, o no lo identificó o dio prioridad a otros aspectos, pero no a la respuesta vinculada con dicha dimensión (Ver Figura 4).

La Dimensión Lenguaje (audiovisual) se encuentra representada por las respuestas a las preguntas 6.3 y 7.1. En la primera de ellas se desvela que un 44,5\% respondió pensando en el lenguaje audiovisual. El resto dio prioridad a otras respuestas: 41,0\% muestra que los amigos pueden ayudarse (que identificaba a la Dimensión Ideología y Valores), parece gracioso (10\%) y no sé $(4,5 \%)$. La pregunta 7.1 invitaba al niño a argumentar las razones de la elección de una imagen fija y revela un resultado

Figura 4- Resumen de las preguntas que forman la Dimensión Ideología y Valores

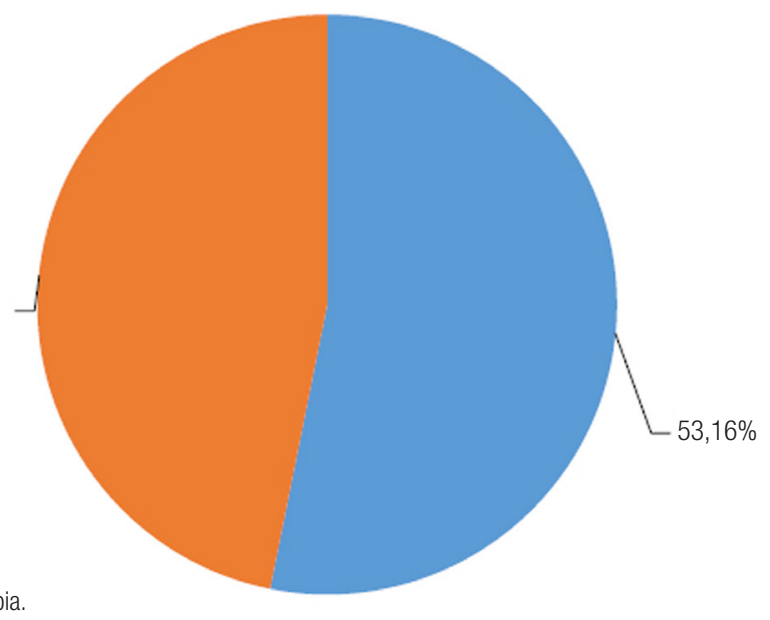

Identifica ideología y valores

No identifica ideologia y valores 0 prioriza otros aspectos 
positivo. Primeramente, en la pregunta 7 se le presenta al alumnado dos fotografías idénticas en la que aparece la imagen de un niño, y se le pide que señale la que se identifica mejor con la frase El niño está triste y tiene frío. La segunda fotografía, con tonos azulados, es la que mejor identifica dicha frase puesto que la vincula con los colores fríos. Esta imagen fue elegida por el $82,3 \%$ de la muestra. Sin embargo, esta pregunta no puntuaba, sino que servía de motivación para la segunda, la 7.1, donde se pide la razón de su elección, ya sea relacionada con el tono azul o no. Un 77,3\% respondió acertadamente mientras que un 18,4\% respondió erradamente y un 4,3\% prefirió elegir no sé. Los ítems que constituyen la Dimensión Lenguaje se muestran en la Figura 5 y el resumen de la misma en la Figura 6.

Figura 5- Preguntas de la Dimensión Lenguaje

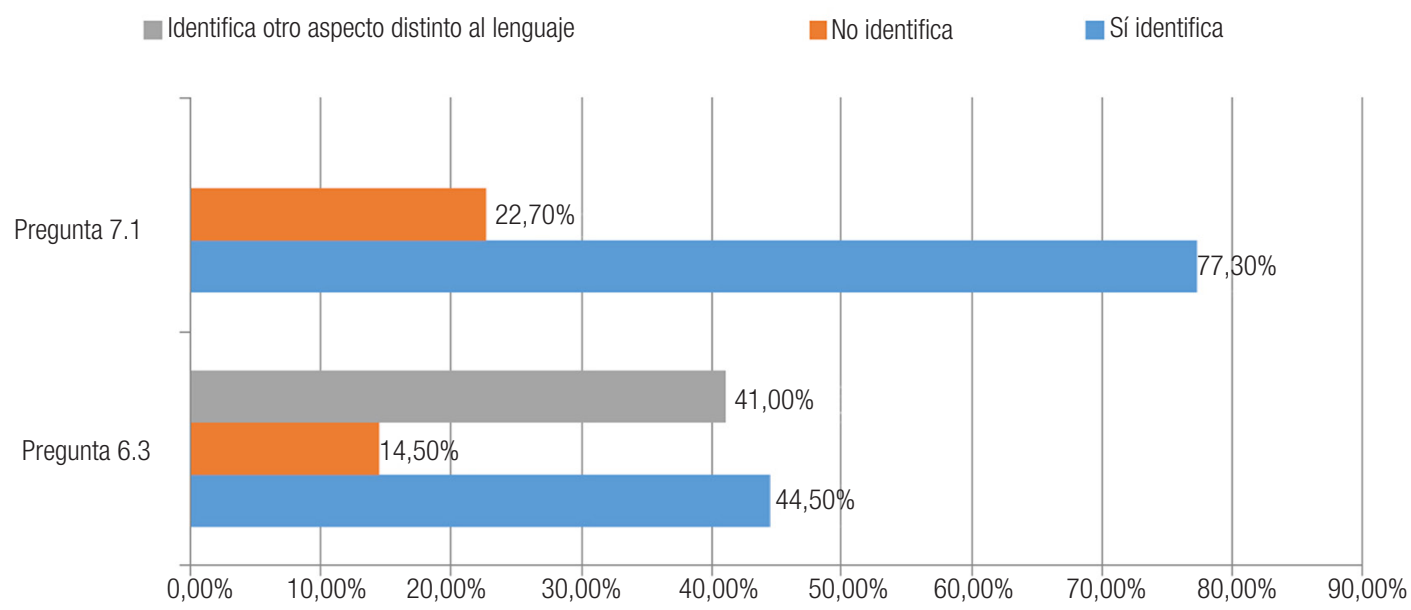

Fuente: Elaboración propia.

Figura 6- Resumen de las preguntas que forman la Dimensión Lenguaje

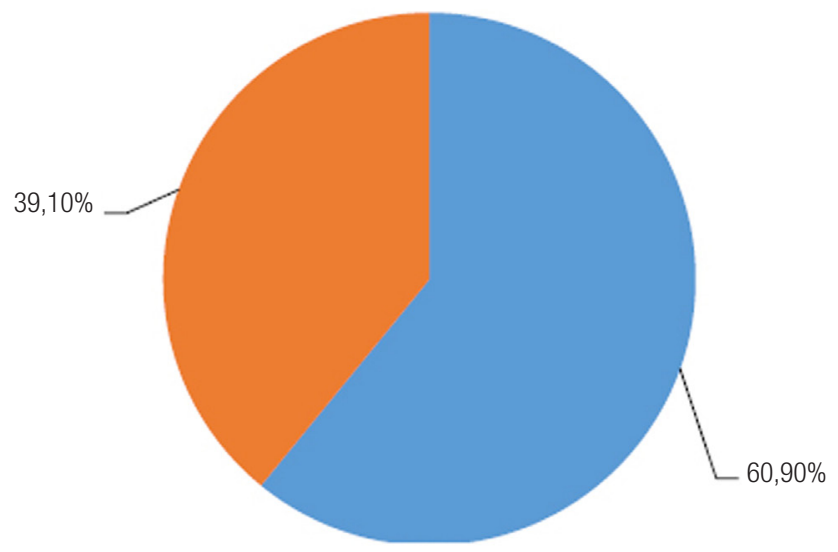

Identifica

No identifica el lenguaje 0 prioriza otros aspectos

Fuente: Elaboración propia. 
La Dimensión Recepción y Audiencia está vinculada con las preguntas 6.4, 6.5 y 8 . La primera pide al alumnado su opinión acerca del anuncio de El niño y el mar en relación a si le convencería a él y a otras personas para comprar el producto. Este responde que sí en el 38,4\% de los casos; sin embargo, manifiesta que le convence a los demás pero no a él en un porcentaje ligeramente superior, un 39,2\%. Por el contrario, un 10,7\% del alumnado considera que no convence a nadie y un $11,7 \%$ no sabe qué opinar al respecto. Si se interroga al alumnado por el motivo por el que le gusta el anuncio de El niño y el mar (pregunta 6.5), un 53,5\% contesta que la historia le resulta emocionante, un $23,1 \%$ responde que el producto tiene un buen sabor, es decir, solo piensa en el producto y un 23,4\% desconoce el motivo. En lo que concierne al concepto de audiencia (pregunta 8), este no es entendido por un porcentaje elevado de alumnos, pues solo el 57\% relaciona el término con su significado. Los ítems sobre esta dimensión se pueden ver en la Figura 7 y su resumen en la 8.

Figura 7- Preguntas de la Dimensión Recepción y Audiencia

- No tiene nociones sobre recepción y audiencia

- Tiene nociones sobre recepción y audiencia

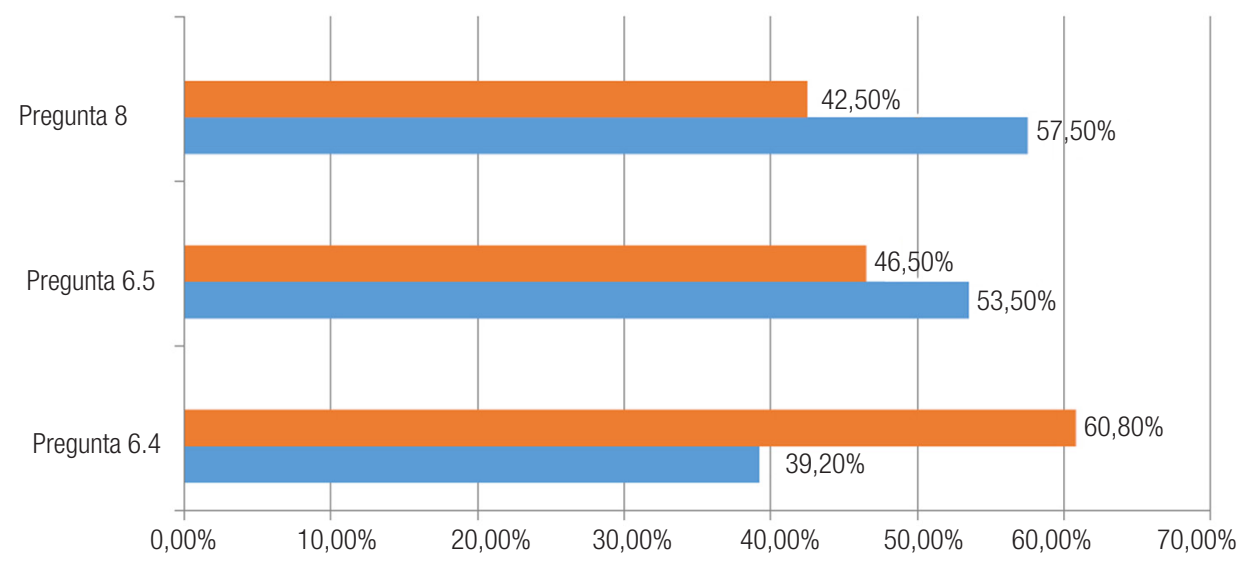

Fuente: Elaboración propia.

Figura 8- Resumen de las preguntas que forman la Dimensión Recepción y Audiencia

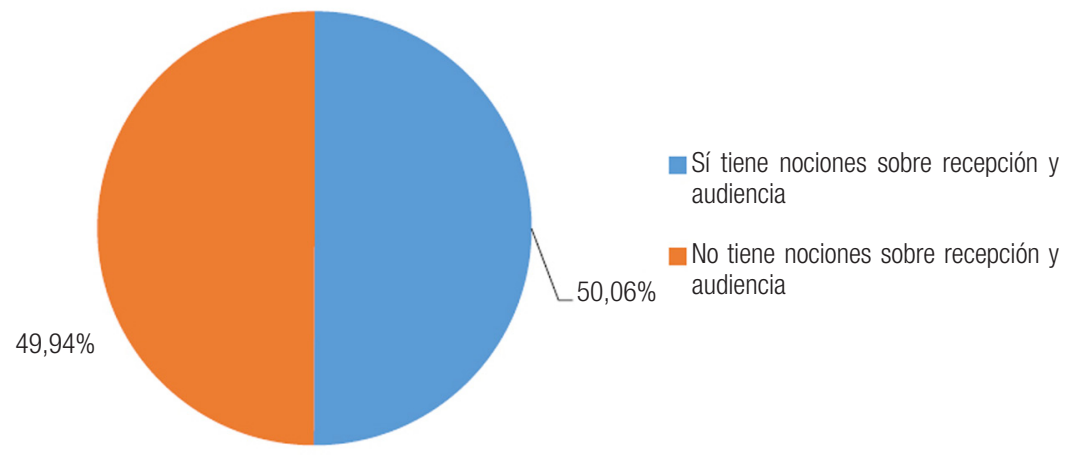


La Dimensión Tecnología se refleja en los items 9 al 12. La pregunta 9 trata sobre conceptos vinculados a esta área del conocimiento, tales como la identificación de las funciones del SMS, el DVD, el canal YouTube o el IPOD. Éstos son conocidos por el alumnado de forma mayoritaria, sobre todo los tres primeros (SMS, DVD y YouTube, ver Tabla 2). De forma global, las puntuaciones máximas son alcanzadas por el 47,3\% del alumnado, las medias llegan a un 36,5 y los niños que apenas conocen un concepto o lo desconocen por completo constituyen el 16,2\%.

Tabla 2- Conceptos acerca de la Dimensión tecnología

\begin{tabular}{|c|c|c|c|c|c|c|c|c|}
\hline \multirow{2}{*}{ Conceptos (SMS, DVD, YouTube, IPOD) } & \multicolumn{2}{|c|}{ SMS } & \multicolumn{2}{|c|}{ DVD } & \multicolumn{2}{|c|}{ YouTube } & \multicolumn{2}{|c|}{ IPOD } \\
\hline & $f$ & $\%$ & $f$ & $\%$ & $f$ & $\%$ & $f$ & $\%$ \\
\hline Correo basura que llega por email & 59 & 10,2 & 10 & 1,7 & 18 & 3,1 & 36 & 6,2 \\
\hline Web para ver, subir y compartir vídeos & 23 & 4,0 & 32 & 5,5 & 462 & 79,5 & 16 & 2,8 \\
\hline Aparato portátil para guardar y ver vídeos, oír música, juegos & 10 & 1,7 & 56 & 9,6 & 48 & 8,3 & 342 & 58,9 \\
\hline Disco para almacenar vídeos, música y datos & 8 & 1,4 & 464 & 79,9 & 19 & 3,3 & 39 & 6,7 \\
\hline Mensaje de teléfono móvil & 434 & 74,7 & 2 & 0,3 & 10 & 1,7 & 27 & 4,6 \\
\hline No lo sé & 47 & 8,1 & 17 & 2,9 & 24 & 4,1 & 121 & 20,8 \\
\hline Total & 581 & 100 & 581 & 100 & 581 & 100 & 581 & 100 \\
\hline
\end{tabular}

$f=$ frecuencia

Fuente: Elaboración propia.

En cuanto al reconocimiento de la transformación de una fotografía a través de un programa informático, el alumnado lo consigue en el 75\% de los casos (pregunta 10). El resto no lo logra (25\%).

En la pregunta 11 se cuestionaba al alumnado por la identificación de botones de acción en un reproductor de vídeo/sonido (reproducir, adelantar, retroceder, pausa y detener o stop), los resultados señalan que solo un $43,9 \%$ consigue dar la respuesta completa de forma correcta. Un 48\% identifica la mayoría de los botones siendo los de pausa y stop los que generaron mayor confusión en la muestra.
Al preguntarle al alumnado por el uso que hace de Internet (pregunta 12), éste tiene la opción de marcar varias respuestas tales como: buscar información para los deberes, usar el correo electrónico, entrar en redes sociales, ver vídeos, jugar o chatear, así como no utilizar la red. En este sentido, las puntuaciones alcanzadas muestran que un $4 \%$ no accede a Internet, un 71,6\% lo hace para ciertas actividades, mientras que un $24,4 \%$ lo hace utilizando todas las opciones dadas. En las figuras 9 y 10 se pueden observar los porcentajes de respuesta por cada ítem de esta dimensión y el resumen que nos aclara cuál fue el resultado final de la muestra en relación con la tecnología.

Figura 9- Preguntas de la Dimensión Tecnología

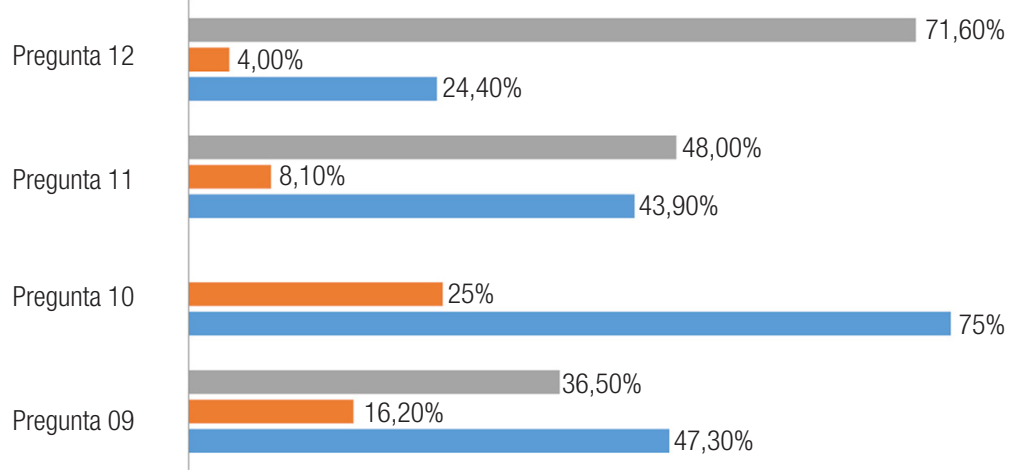

Conoce solo algunos aspectos sobre tecnología

Conoce un solo concepto o los desconoce por completo

Tiene nociones sobre tecnología 


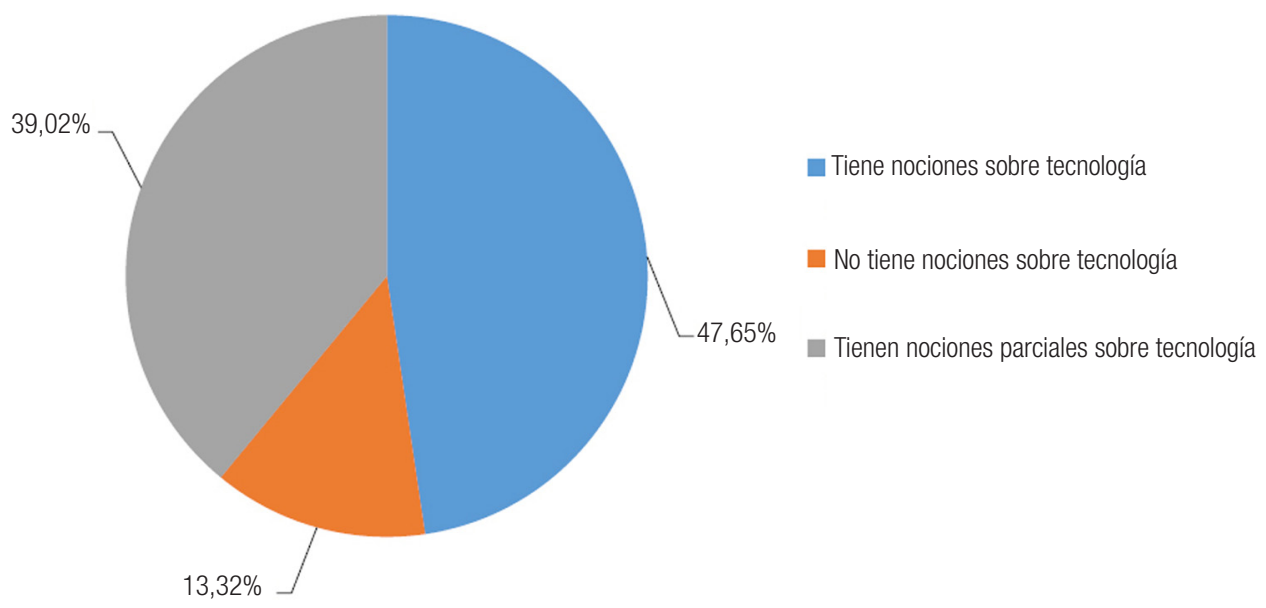

Fuente: Elaboración propia.

La Dimensión Producción y Programación se fundamenta en los ítems 13 al 16. En lo que concierne al reconocimiento de profesiones vinculadas con los medios de comunicación (pregunta 13) se ha podido comprobar que el resultado es bastante bajo. Caso excepcional lo constituyó en concreto la identificación de tareas del guionista, que es reconocido por el $60,9 \%$ de los participantes. Respecto al concepto de casting (pregunta 14), los participantes lo reconocen en el 69,9\% de los casos, un 6,4\% desconoce el término mientras que el resto $(23,7 \%)$ reconoce que está relacionado con el mundo audiovisual pero no sabe qué significa. El concepto de copia pirata (pregunta 15) también es identificado por la mayoría de los participantes, en este caso, en un 83\% de los casos. Y por último, la pregunta 16 invitaba al niño a ordenar los pasos necesarios para realizar una película. Tal como se puede ver en la Tabla 3, los porcentajes de acierto completo son bastante bajos, un 13,3\% conoce cómo ordenar los pasos mientras que un 38,7\% no acertó ninguno de ellos. Las puntuaciones alcanzadas por el alumnado en la Dimensión Producción y Programación se aprecian en el Figura 11 y el resumen en la Figura 12.
Tabla 3- Puntuación en la identificación de los pasos seguidos en la grabación de una película.

\begin{tabular}{|c|c|c|}
\hline Puntuación & Frecuencia & Porcentaje \\
\hline 0 puntos (0 aciertos) & 225 & 38,7 \\
\hline 1 punto (1 acierto) & 99 & 17 \\
\hline 2 puntos (2 ó 3 aciertos) & 180 & 31 \\
\hline 3 puntos (4 aciertos) & 77 & 13,3 \\
\hline Total & 581 & 100 \\
\hline
\end{tabular}

Fuente: Elaboración propia.

Una vez que se ha puesto de manifiesto cuál es la realidad del nivel de competencia mediática que posee el alumnado participante, pensábamos que era necesario comprobar si sus respuestas se encontraban vinculadas a algún factor personal como es el género y la edad. Por ello, con la finalidad de comprobar la relación y asociación existente entre estas variables independientes y las dependientes procedimos a realizar las siguientes pruebas: Chi-cuadrado, coeficiente de contingencia, coeficiente $V$ de Cràmer y coeficiente $p h i$. 
Figura 11- Preguntas de la Dimensión Producción y Programación

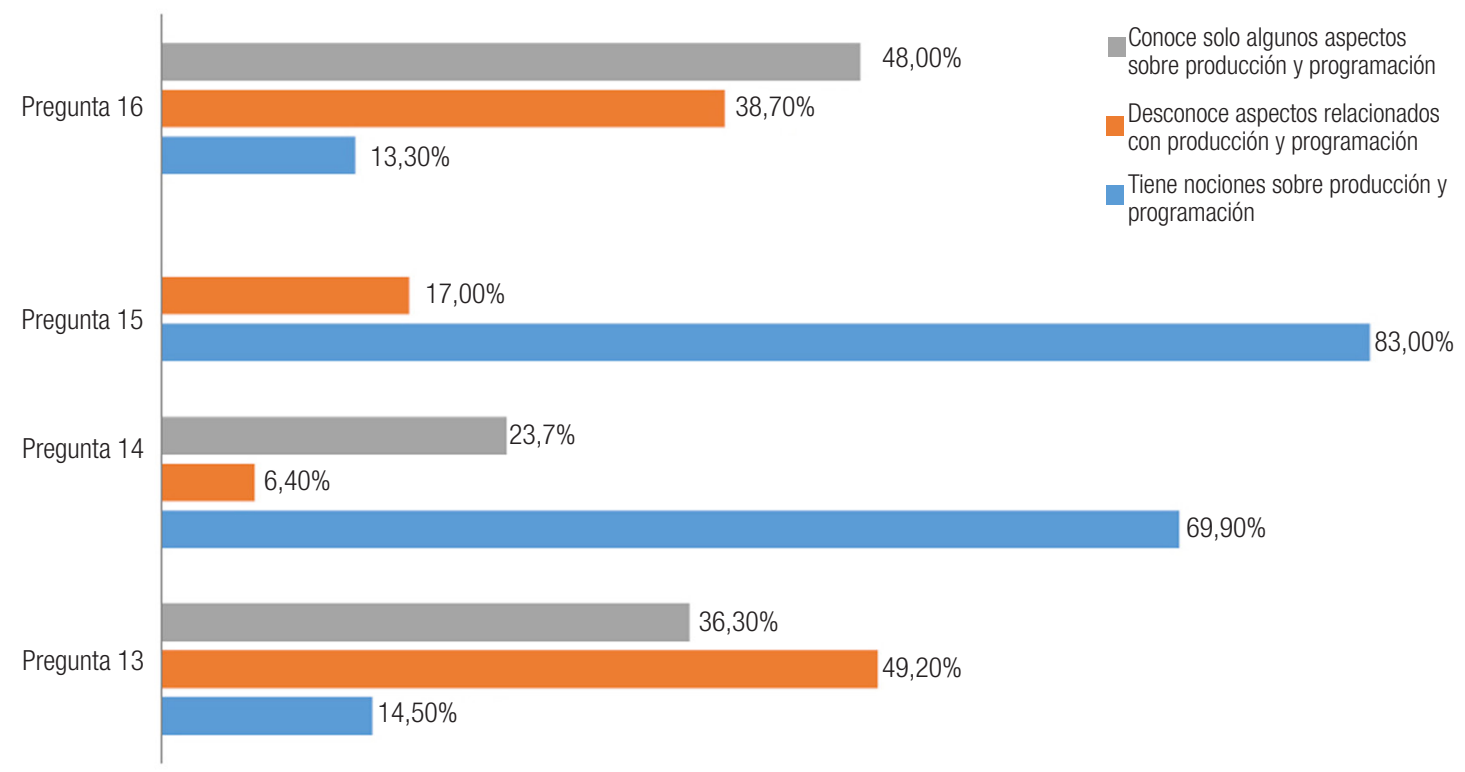

Fuente: Elaboración propia.

Figura 12- Resumen de las preguntas que forman la Dimensión Producción y Programación

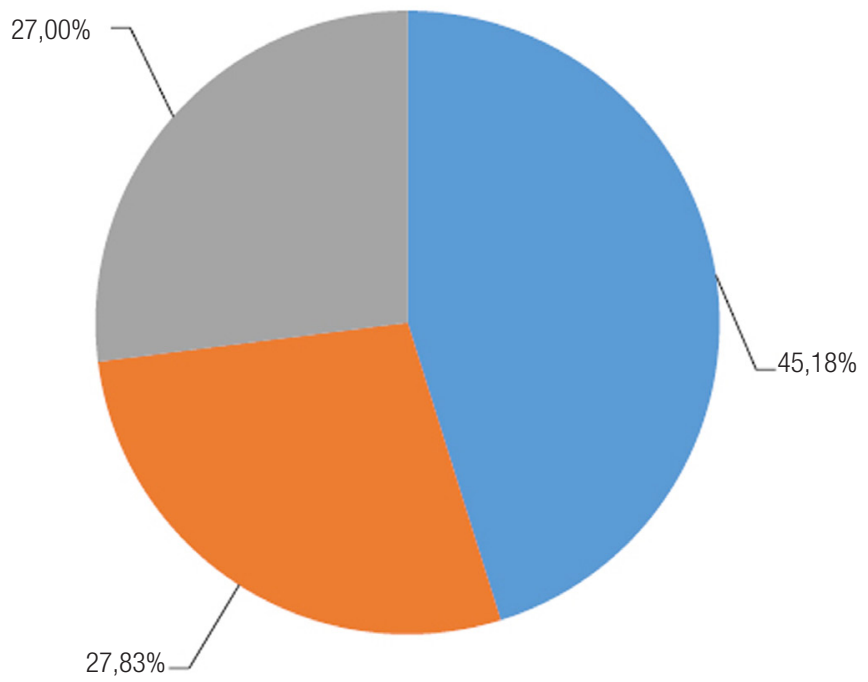

Conoce solo algunos aspectos sobre producción y programación

Tiene nociones sobre producción y programación

Tiene nociones parciales sobre producción y programación

Fuente: Elaboración propia.

De su análisis, se puede deducir que tanto el sexo del alumnado como la edad del mismo, condiciona la respuesta dada a preguntas sobre la persuasión que genera el anuncio El niño y el mar para comprar producto de cacao Nesquik o sobre el reconocimiento del concepto de audiencia. En el primer caso, las niñas son las que perciben en mayor porcentaje que los niños esta persuasión y a mayor edad del alumnado más percepción de dicha persuasión. En el 
segundo caso, en la identificación del concepto de audiencia son los niños quienes en un porcentaje mayor lo definen de manera correcta y de igual modo, a mayor edad del alumnado, mayor identificación de dicho concepto.

El sexo también provoca que las respuestas de niños y niñas sean diferentes en preguntas como la elección de un anuncio $\mathrm{u}$ otro, el motivo de dicha elección, la elección de la fotografía y el motivo de su selección y en el concepto de casting.

Las niñas eligen más el segundo anuncio (Los niños cantando) que el primero (El niño $y$ el mar); sin embargo, son los niños quienes reconocen que se parece a una película en mayor medida, mostrando, por tanto, una mayor competencia en la dimensión Estética. Por el contrario, son las niñas quienes eligen más la segunda fotografía y reconocen en mayor medida las tonalidades frías que se corresponden con el enunciado de la fotografía El niño está triste y tiene frío, demostrando así una mayor competencia en la dimensión Lenguajes. Asimismo, las niñas responden de manera correcta el concepto de casting en mayor medida que los niños, lo que muestra niveles más altos de competencia en este aspecto de la dimensión Recepción.

En lo que concierne a la edad, el alumnado que cuenta con 10 años de edad selecciona la respuesta adecuada en mayor proporción que los que han cumplido 9 u 11 años de edad, atribuyéndose mayor competencia en este aspecto de la dimensión Lenguaje, mientras que la competencia de la dimensión Tecnología, representada entre otras cuestiones en el reconocimiento acertado del concepto DVD, se desarrolla en mayor medida por parte de los alumnos que presentan mayor edad, 11 años, en segundo lugar $10 \mathrm{y}$, finalmente, 9 años.

\section{Conclusiones}

De esta investigación podemos destacar una cuestión importante: los niños de cuarto nivel de primaria en España no conocen tantos aspectos sobre la competencia mediática como podemos suponer, les falta aún mucho camino por recorrer para ser considerados competentes en el sentido mediático. Si bien es cierto que la escasa experiencia de vida que puede tener un niño de esas edades -10 años en promediole impide realizar ciertos razonamientos en relación con los medios de comunicación, hay que reconocer que cuentan con saberes que otras generaciones desconocían. Los niños se han visto en la necesidad de afrentar la tecnología -quizás debido a la exposición de distintas ventanas digitales a las cuales tienen acceso- sobre todo desde el enfoque de lapráctica pero no cuentan con fundamentos conceptuales ni críticos para desenvolverse en el mundo infoxicado de hoy.

En primer lugar podríamos afirmar que, según los resultados obtenidos en este trabajo de investigación, en el sentido estético los niños no cuentan con la suficiente información ni capacidad de respuesta acertada para ser considerados competentes. Solo un 20\% realizó una selección adecuada de respuestas que dejarían ver este tipo de punto de vista. En cuanto a la identificación de ideologías y valores en los contenidos audiovisuales analizados, la muestra demostró que la mitad de ellos aproximadamente es capaz de reconocer tales ideologías y valores. Llama la atención que muchos de ellos, un 44\%, identificó un valor que no se estaba preguntando sino otro distinto. Esto puede indicar que los niños tienen una idea aproximada de que los contenidos transmiten ciertas ideologías y valores pero no siempre los pueden reconocer a primera vista.

Otra cuestión es la identificación del lenguaje audiovisual. En este aspecto los niños tienen más conocimiento, según nuestro estudio. Un 60\% de ellos identificó cuestiones relacionadas con la imagen en movimiento, el color, la música. No obstante, sucede algo similar que con la dimensión ideología $y$ valores, pues un 41\% identificó otros aspectos distintos al lenguaje audiovisual. En relación a los niños como receptores de los medios y como 
parte de la audiencia, el resultado muestra una similitud -casi extraordinaria- entre los que tienen nociones y los que no. Podría afirmarse que la mitad de ellos demostró tener ciertos conocimientos sobre lo que significa ser receptor del medio audiovisual y también ser audiencia. Es decir, pueden situarse como espectadores que viven la experiencia producidas por los medios de comunicación.

En materia de tecnología los niños, como puede ser previsible y según este estudio, tienen suficientes nociones. Concretamente, cerca de un $48 \%$ puede considerarse que respondió de forma acertada a todas las preguntas que componían esta dimensión mientras que casi un 40\% demostró algún conocimiento -no todo- relacionado con la tecnología. De esta manera solo un 13,5\%, aproximadamente, no fue capaz de responder acerca de este tipo de conocimiento. Algo similar sucede ante las cuestiones relacionadas con la producción audiovisual y la programación de televisión. Un 45\% tiene nociones completas y un 27\% nociones parciales sobre este contenido. La diferencia es que en este caso más de un cuarto de la muestra demostró ignorar cómo es el universo detrás de las cámaras.

Evidentemente, falta mucho camino por recorrer, es indudable que no nos podemos conformar con los resultados de un estudio puntual y cuantitativo para señalar que los niños cuentan con ciertos conocimientos sobre la competencia mediática. Es necesario sistematizar el aprendizaje en la escuela y reforzar en la familia este tipo de información que, sin duda, le servirá para aprovechar mejor los medios e impedir la manipulación a la que pueda estar expuesto en un mundo digitalizado como el de hoy.

\section{Referencias}

AGUADED, Ignacio; PÉREZ-RODRÍGUEZ, Amor. Estrategias para la alfabetización mediática: competencias audiovisuales y ciudadanía en Andalucía. New Approaches in Educational Research, Alicante, v. 1, n. 1, p. 25-30, 2012.

BISQUERRA, Rafael. Métodos de investigación educativa: guía práctica. Barcelona: CEAC, 2004.

COMISIÓN EUROPEA. Recomendación de la Comisión sobre la alfabetización mediática en el entorno digital. 2013. Disponible en: <http://g00.gl/dy1NZh>. Acceso en: 19 nov. 2014.

FERRÉS, Joan. La competencia en comunicación audiovisual: propuesta articulada de dimensiones e indicadores. Comunicar, Huelva, v. 15, n. 29, p. 100-107, 2007.

FERRÉS, Joan; AGUADED, Ignacio; GARCÍA-MATILLA, Agustín. La competencia mediática de la ciudadanía española: dificultades y retos. Icono14, Madrid, v. 10, n. 3, p. 23-42, 2012. Disponible en DOl: 10.7195/ri14.v10i3.201. Acceso em: 19 nov. 2014.

FERRÉS, Joan; PISCITELLI, Alejandro. La competencia en educación mediática: propuesta articulada de dimensiones e indicadores. Comunicar, Huelva, v. 19, n. 38, p. 75-82, 2012. Disponible en: D0l:10.3916/C38-2011-02-08. <file:///C:/Users/usuario/ Downloads/Comunicar-38-Ferres-Piscitelli-75-82.pdf>. Acceso en: 19 nov. 2014.

FERRÉS, Joan et al. Competencia mediática. In: FERNÁNDEZ-CAVIA, José et al. Investigación sobre el grado de competencia de la ciudadanía en España. Madrid: Instituto de Tecnología Educativa, 2011. p. 19-204.

GARCÍA-LLAMAS, José Luis. Métodos de investigación en educación: investigación cualitativa y evaluativa. Madrid: UNED, 2003.

MARTA, Carmen. El proceso de recepción televisiva como interacción de contextos. Comunicar, Huelva, v. 16, n. 31, p. 35-40, 2008. Disponible en: D0l: 10.3916/c31-2008-01-004. <file:///C:/Users/usuario/Downloads/Comunicar-31-Marta-35-40.pdf>. Acceso en: 19 nov. 2014.

MARTíNEZ GONZÁLEZ, Raquel. La investigación en la práctica educativa: guía metodológica de investigación para el diagnóstico y evaluación en los centros docentes. Madrid: CIDE/MEC, 2007. 
PÉREZ-RODRÍGUEZ, Amor; DELGADO, Águeda. De la competencia digital y audiovisual a la competencia mediática: dimensiones e indicadores. Comunicar, Huelva, v. 20, n. 39, p. 25-34, 2012. Disponible en: D0I: 10.3916/C39-2012-02-02. <file:///C:/Users/ usuario/Downloads/Comunicar-39-Perez-Rodriguez-Delgado-25-34.pdf>. Acceso en: 19 nov. 2014.

PRENSKY, Marc. Digital natives, digital immigrants. On the horizon. MCB University Press, Lincoln, v. 9, n. 5, p. 1-6, 2001. Disponible en: <http://goo.gl/sMkqJi>. Acceso en: 19 nov. 2014.

VON FEILITZEN, Cecilia; CARLSSON, Ulla; UNESCO International Clearinghouse on Children and Violence on the Screen (Ed.). Children and media: image, education, participation. Nordicon: Goteborg University, 1999. Yearbook from the UNESCO International Clearinghouse on Children and Violence on the Screen.

Recibido en: 24.11.2014

Aprovado en: 24.03.2015

Antonia Ramírez García es doctora por la Universidad de Córdoba. Licenciada en geografía e historia y en psicopedagogía. Profesora contratada doctora (acreditada titular de universidad) y vicedecana de relaciones institucionales e internacionales de la Facultad de Ciencias de la Educación de la Universidad de Córdoba, España.

Jacqueline Sánchez-Carrero es doctora en comunicación audiovisual, máster en comunicación audiovisual en el espacio iberoamericano y licenciada en periodismo. Investigadora en educación mediática. Directora de Taller Telekids, alfabetización mediática para niños.

Paloma Contreras-Pulido es doctora en comunicación y educación por la Universidad de Huelva. Periodista y educadora social. Miembro del Grupo de Investigación Ágora. Docente del máster de comunicación y educación audiovisual y del grado de educación social de la Universidad de Huelva. 